Article

\title{
Evaluation of Geological and Ecological Bearing Capacity and Spatial Pattern along Du-Wen Road Based on the Analytic Hierarchy Process (AHP) and the Technique for Order of Preference by Similarity to an Ideal Solution (TOPSIS) Method
}

\author{
Zhoufeng Wang ${ }^{1, * \mathbb{D}}$, Xiangqi He ${ }^{1}$, Chen Zhang ${ }^{1}$, Jianwei $\mathrm{Xu}^{1}$ and Yujun Wang ${ }^{2}$ \\ 1 School of Geoscience and Technology, Southwest Petroleum University, Chengdu 610500, China; \\ 201922000062@stu.swpu.edu.cn (X.H.); 201721000107@stu.swpu.edu.cn (C.Z.); \\ 201822000076@stu.swpu.edu.cn (J.X.) \\ 2 Hefei Surveying and mapping Institute, Hefei 230031, China; wangyujun@hfchy.com \\ * Correspondence: wangzf@swpu.edu.cn; Tel.: +86-1308-446-4702
}

Received: 14 March 2020; Accepted: 8 April 2020; Published: 10 April 2020

\begin{abstract}
As China is a mountainous country, a large quantity of the population has to live in mountainous areas due to limited living space. Most of them cluster along roads in areas with relatively poor traffic conditions. In view of the spatial-temporal change of complex geological and ecological environment along the roads in the mountains, this paper takes the Dujiangyan- Wenchuan (Du-Wen) Road as the research object, and puts forward a method to evaluate the bearing capacity of regional geological and ecological environment based on the evaluation of quality and spatial coupling of bearing capacity. For the needs of the current research, a total number of 20 indicators from three aspects of geological, ecological, and social attributes were selected to carry out the assessment. Based on the GIS platform and evaluation index system, the weight of each evaluation index factor is determined by Analytic Hierarchy Process (AHP). The comprehensive quality of bearing capacity is calculated by the Technique for Order of Preference by Similarity to an Ideal Solution (TOPSIS) algorithm through weighted superposition, which comes to result in the evaluation of geological, ecological, and social environment. Afterward, the bearing capacity of the study area is classified, combining the results of hot spot analysis. The study shows that the spatial distribution of geological, ecological, and socio-economic bearing capacity in this area is highly aggregated, with $31.12 \%$ of the area to be classified as suitable construction area, 31.98\% as backup reserve area, and $36.79 \%$ as unsuitable construction area. The studied triangle area, composed of Yingxiu Town, Xuankou Town, and Dujiangyan City, presents a large area of a high-valued aggregation area, with comprehensive high quality bearing capacity and spatial aggregation, which is better for planning and construction.
\end{abstract}

Keywords: bearing capacity; analytic hierarchy process; geographical survey of national conditions; hotspot analysis; topsis algorithm

\section{Introduction}

China is a mountainous country, with mountainous areas accounting for $69 \%$ of the country's total land area; and whose flat areas, suitable for human habitation and production activities, such as plains and basins, are extremely limited. At the same time, China has a large population and a growing shortage of living space. For example, $56 \%$ of the population has to live in mountainous areas, where transportation is inconvenient and production activities are not suitable. Sichuan Province is located in the southwest of China, with a large area of mountains. Except for the Sichuan Basin, which is 
dominated by low and medium mountains and hills, the surrounding areas of the basin are dominated by medium and high mountains, with steep terrain and widely geological disasters. In particular, the Wenchuan earthquake, in 2008, made the geological environment very fragile. According to the data from Sichuan Provincial Department of Transportation in 2016, the total mileage of national roads and provincial roads in Sichuan Province has reached 22,526 kilometers, of which, 11,793 kilometers are located at the edge of the basin or the surrounding plateau area, accounting for $52.4 \%$ of the total mileage. A violent debris flow hazard occurred in Wenchuan, Sichuan Province in August 20, 2019; the flood disaster caused by the rainstorm killed 16 people, and 22 people lost contact. The direct economic loss was 3.6 billion yuan.

With the sustained and rapid development of China's economy, the interference of mankind's social activities on the natural ecosystem is also intensifying, leading to the continuous deterioration of the natural environment. Solving the contradiction among resources, population, and environment, achieving harmony between man and nature, and achieving coordinated development, become the inherent requirements to ecological civilization construction. The adaptation of ecological civilization construction and economic development is the prerequisite for sustainable development. Ma and Ma [1] have proposed that environmental carrying capacity refers to the ability of the environmental system to undergo no structural changes during a period of time and in a certain geographical area, while maintaining its normal functioning, the total amount of human beings and various economic activities that the environmental system can withstand.

In recent years, Chinese scholars have carried out various research on the comprehensive bearing capacity evaluation of different regions. Some studies are carried out on a national scale, such as Liu's [2] comprehensive evaluation of China's water resources carrying capacity. Some are provincial; Liu et al. [3] have studied dynamic evaluation of regional comprehensive carrying capacity in Henan Province. Others are about specific cities, such as Lu et al.'s [4] analysis of ecological environment resources carrying capacity of Guiyang City. Studies on single element bearing capacity mainly include the following aspects: Li [5] studied the land ecological security of Dujiangyan City, while Wang et al. [6] compared the ecological bearing capacity of the upper reaches of Shiyang River in time evolution. Liu et al. [7] studied the evaluation of geo-environmental carrying capacity of the Wulonggou mine, based on the spatial statistical analysis method. What was used mainly include: Yang et al. [8] used the Analytic Hierarchy Process (AHP) comprehensive evaluation method, Feng et al. [9] used the Technique for Order of Preference by Similarity to an Ideal Solution (TOPSIS) algorithm, Zheng et al. [10] used the ecological footprint method. The research direction of bearing capacity mainly focuses on the following three aspects: $\mathrm{Gu}$ [11] elaborated the development of bearing capacity concept in different periods, $\mathrm{Xu}$ et al. [12] evaluated the bearing capacity of traffic environment in Beijing, and Wang et al. [13] planed the development area based on the bearing capacity. Taking the planning area as an example, Ni [14] divided the quality of land in Qushui region of Tibet; Tong [15] divided the land use of Wuhan city; Wang et al. [16] divided the area along Du-wen Road into comprehensive areas, including the agricultural development area, ecological restoration area, construction suitable area, fault avoidance area, and conversion of farmland to forest area.

After entering the 21st century, based on the research on the basic concepts and theories of bearing capacity, domestic scholars have carried out rich researches on regional "ecological environment bearing capacity" and "geological environment bearing capacity" for the perspective of "nature-economy-society" coordinated development. Ma and Jiang $[17,18]$, respectively, took the Beijing Tianjin Hebei and Yangtze River economic belt as research objects, analyzed the land, resources, and environmental conditions, and other major geological factors of this economic belt. Zhang et al. [19] carried out the risk-based assessment of geological environment bearing capacity, put forward the concept of a risk-based geological environment bearing capacity and ultimate bearing capacity, and distinguished the bearing capacity status into three grades: safe bearing, allowable overload, and unacceptable overload, which has important reference value for the delineation of geological disaster red line. 
Meng et al. [20] conducted a background test evaluation on the bearing capacity of the geological environment in China.

In the existing research system of an earthquake mountainous area, the system model method is often used to evaluate the bearing capacity of regional resources and environment, and the comprehensive quality evaluation of bearing capacity is used to calculate regional population and carry out industrial planning. Based on the Vigor-Organization-Resilience model [21] coupled with ecosystem services, Zhu [22] quantitatively evaluates the ecosystem health in Wenchuan earthquake area while Tang [23] built the model of the bearing capacity of resources and environment in the mountainous earthquake area, according to the derivation from the stress mechanism. Fan [24] evaluated the bearing capacity of resources and environment in the reconstruction in the Lushan area after the earthquake by using the AHP comprehensive evaluation method; there is still lack of research on the spatial-temporal dynamic evolution of the bearing capacity of resources and the environment in the mountainous earthquake area. Mountainous area accounts for a large proportion of the land area in China where earthquakes, along with other kinds of secondary disasters, occurred frequently and often caused serious damage. Reconstruction and recovery in these areas are becoming more difficult; meanwhile, the basic conditions for economic and social development are more arduous. Given to the situation stated above, it is of great practical significance to carry out the research on the bearing capacity of the seismic mountainous area.

The above research enriches the theories and methods of bearing capacity, but the existing research mainly focuses on the quantitative evaluation of bearing capacity. Due to different natural, social, and economic conditions in each study area, as well as the diversity of the evaluation factor selection and the application of evaluation methods in bearing capacity research, a mature, complete, and recognized research system has not been formed in the process of quantitative measurement. There are few studies on the spatial distribution pattern in the evaluation of regional bearing capacity. It is difficult to find correlation among bearing capacity quality, scale, and spatial distribution. The comprehensive evaluation of bearing capacity needs to be considered from aspects of comprehensive development suitability and spatial stability. It is necessary to consider the suitability of development from the perspective of comprehensive quality, and to consider the spatial stability of sustainable development from the perspective of spatial layout.

The main objectives of current research were (1) Establishing three evaluation index systems for geological environment, ecological environment, and socioeconomics, which are suitable for the three major geomorphic areas of Sichuan Basin edge area, Southwest Sichuan mountain area, and Northwest Sichuan Plateau area. (2) Studying the integration between the national geographical monitoring data and ecological environment bearing capacity evaluation index system, based on the background database of the geo-ecological conditions. (3) Using AHP to reasonably determine the weight of each index, combining with the comprehensive evaluation method and establishing the mathematical model of geological ecological environment bearing capacity. (4) Based on this, the comprehensive quality score of bearing capacity is used as a spatial variable, and the hotspot analysis tools are used to analyze the spatial agglomeration characteristics of the comprehensive quality of bearing capacity in the study area. The research results realize the coupling of bearing capacity quality, scale, and spatial distribution pattern, provide scientific basis for the development and planning along Du-Wen Road.

\section{Materials and Methods}

\subsection{Study Area}

The study area is located in Wenchuan County, Sichuan Province, China. The geographical range is $103^{\circ} 14^{\prime} \sim 103^{\circ} 45^{\prime}$ east longitude, $30^{\circ} 54^{\prime} \sim 31^{\circ} 36^{\prime}$ north latitude, and the area is $925 \mathrm{~km}^{2}$. There are the Maowen Fault and Yingxiu Fault along the Du-Wen Road in this study area, and Yingxiu Fault is the seismogenic fault of the "5. 12" earthquake (see Figure 1). 


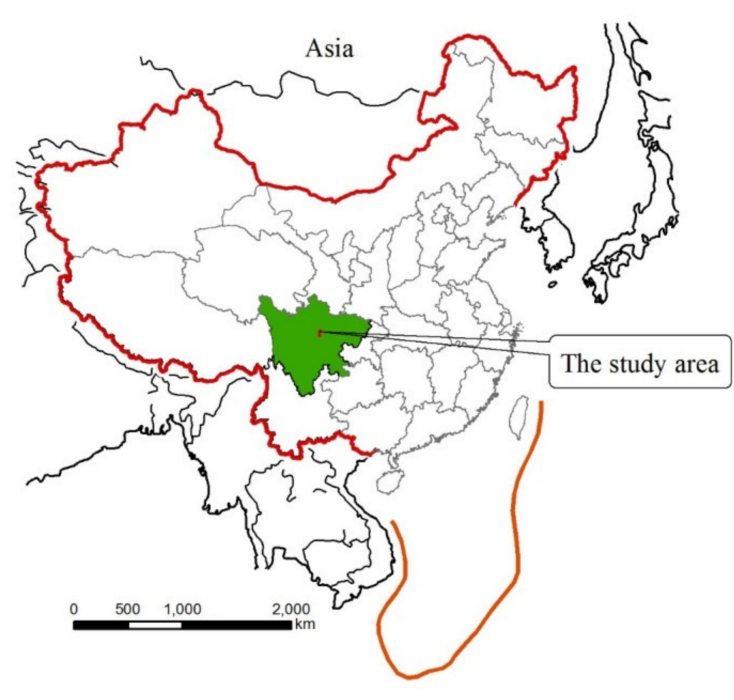

(a)

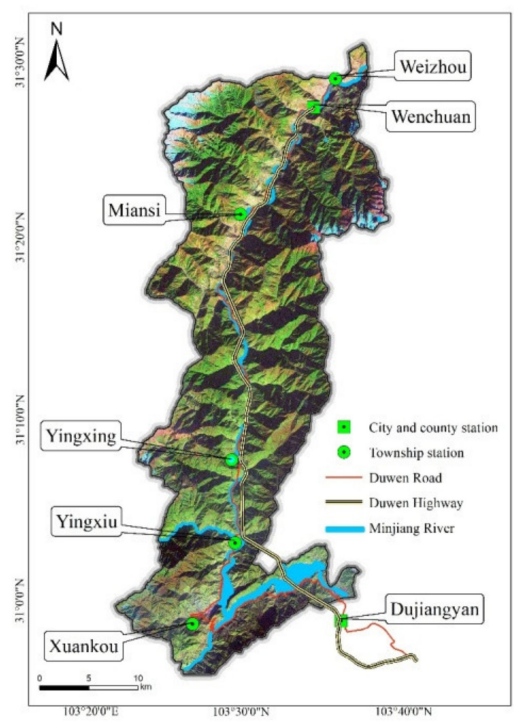

(b)

Figure 1. (a) Location of the study area, Sichuan Province, China; (b) remote sensing image map of Dujiangyan-Wenchuan Road.

This area is located between the Longmen Mountains and the Qionglai Mountains in the highland plateau area of western Sichuan. It belongs to the transitional zone between the Chengdu Plain and the northwestern plateau of Sichuan. It has steep internal terrain, high mountains, and steep valleys. The average slope of mountains along the road is $30^{\circ} \sim 35^{\circ}$, with the Maowen Fault and Yingxiu Fault being the main geologic constructions. The Yingxiu Fault was the tremor of the " 512 " Wenchuan Earthquake. The study area is an important source of water conservation of the Yellow River and the Yangtze River. It belongs to the continental monsoon climate. The precipitation is unevenly distributed in the region, affected by the mountain blockage in the territory. It gradually decreases from northwest to southeast as the terrain decreases, with the most in August and the least in January. The natural rivers in the area belong to the main stream of the Lancang River and its tributaries. The larger tributaries include Yuzi River, Caopo River, Shouxi River, etc. There is also an artificial river, the Dujiangyan Irrigation River. As located in the area of the Longmen Mountain seismic belt, the geological structure is complex, with completed tectonic development and the stratigraphic excavation, diversified lithology. Meanwhile, the summer rainfall is abundant; it is easy to generate landslides and other geological disasters. The research on bearing capacity evaluation here will play a great practical and exemplary role.

The basic data used in this paper is derived from the first national survey of geographic conditions in Sichuan Province. With wide coverage, various types, and high quality, the data can nearly completely reflect the situation of the research area. It contents: 1) the basic status, such as type, quantity, location, scope and area, of natural geographical elements, including the topography, the distribution of disaster points, the coverage of vegetation, the waters and the land. 2) The basic data of human geography elements, including categories, locations, and scopes of transportation facilities, residential areas, public service facilities and energy supply, which are closely related to human activities. This national survey on geographic conditions has comprehensive geospatial information. By transforming the results, we can better serve the local economic construction and promote regional social development.

\subsection{Data}

The data involved in this paper mainly include the census data of the first national geographical conditions in Sichuan province (including types of land cover, roads, waters, structures, and geographical units). It also includes fault zone data and formation lithology data (from 1:200,000 
digital geological map), seismic intensity data (from the Wenchuan 8.0 earthquake intensity distribution map of the China Seismological Bureau). There are data of geological hazard points, data of multi-year average precipitation, soil erosion data, Digital Elevation Model data (30 meters), raster data of land use type (30 meters), data of geological hazard points in 2018, and Point of Information data for 2018, from the Resources and Environment Data Center, Chinese Academy of Sciences. It also includes road data at all levels, water system data (reservoirs, rivers, ditches, etc.), data on settlements, place-name data of settlement place, administrative boundary data (dot, line, plane) from the National Geomatic Center of China; statistical yearbook of Wenchuan County People's Government, including the statistics of society, population, and GDP.

\subsection{Methodology}

\subsubsection{Overall Methodological Framework}

First, research on the bearing capacity constructs the evaluation research framework of the geological ecological environment bearing capacity. Then, the regional bearing capacity status evaluation index system is constructed, which includes three target levels of environment, geologic environment, ecological environment, and social economy, according to the first national geographical survey data of Sichuan Province. It is divided into several evaluation indicators. GIS and Remote Sensing technology are applied to preprocess the data of evaluation indicators, quantify each index factor, and divide the quantified results into five grades. AHP is then used to calculate and assign weights to each indicator. Finally, the TOPSIS method is used to calculate the comprehensive index of geological and ecological environmental bearing capacity of the study area through weighted superposition. The zoning rules, high-value clustering area, low-valued aggregation area, and no significant point area, are used to classify the bearing capacity of the study area through weighted superposition. Thus, the bearing capacity of the study area is comprehensively evaluated, the spatial agglomeration characteristics of the bearing capacity is analyzed, the temporal and spatial distribution of the bearing capacity of the study area is explored, and the priority area of the bearing capacity is delineated. The Overall Methodological Framework is shown as Figure 2.

\subsubsection{Basic Theory of AHP}

The Analytic Hierarchy Process (AHP) developed by Satty, provides a framework for dealing with decision-making problems and complex problems [25]. This paper chooses analytic hierarchy process (AHP) to determine the weight of the index. The basic idea of AHP to solve the problem is consistent with people's thinking of a multi-level, multi factor, and complex decision-making problem. Its most prominent feature is layer comparison and comprehensive optimization, which can provide a simple decision-making method for regional bearing capacity evaluation.

The basic principles of AHP can be summarized as defining and determining the problem; decomposing the problem in a hierarchy from top through the intermediate levels; constructing a set of pair-wise comparison matrices; testing the consistency index; synthesizing the hierarchy to find out the ranks of the alternatives [26]. The implementation steps are listed as follows.

(1) In the AHP, nine scales are usually used to determine the relative importance of each index. The specific meanings of the scales ranges from 1 to 9 are shown in Table 1.

(2) Building the judgment matrix. A pair wise comparison was used for each index, according to the scale value of each index, yielding a $\mathrm{n} \times \mathrm{n}$ matrix, where diagonal elements were equal to 1 . The matrix is shown in Table 2. 


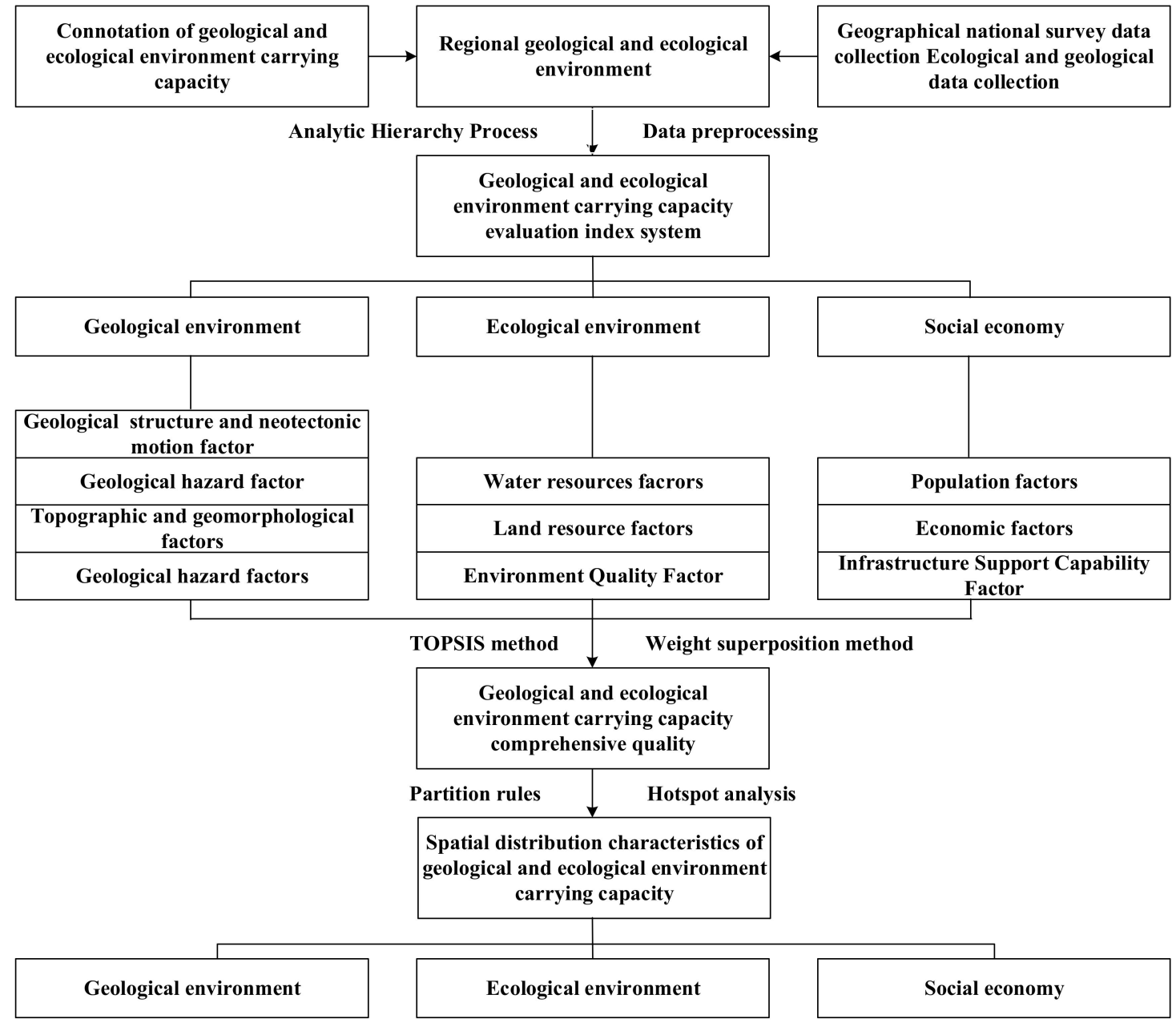

Figure 2. Overall Methodological Framework. TOPSIS $=$ Technique for Order of Preference by Similarity to an Ideal Solution.

Table 1. Meanings of 1-9 Index Scale of the Analytic Hierarchy Process (AHP) method.

\begin{tabular}{cc}
\hline Scale $\mathbf{a}_{\mathbf{i}, \mathbf{j}}$ & Meaning \\
\hline $\mathbf{1}$ & Index $i$ is equally important as index $j$. \\
$\mathbf{3}$ & Index $i$ is weakly more important than index $j$. \\
$\mathbf{7}$ & Index $i$ is moderately more important than index $j$. \\
$\mathbf{9}$ & Index $i$ is very more important than index $j$. \\
$\mathbf{2 , 4 , 6 , 8}$ & Index $i$ is extremely more important than index $j$. \\
Teciprocal $\mathbf{a}_{\mathbf{j i}}=\mathbf{1} / \mathbf{a}_{\mathbf{i}, \mathbf{j}}$ & The comparison of the importance of index $i$ and index $j$ lies between two levels. For \\
& The judgment value obtained by comparing index $j$ with index $i$ is the reciprocal of $a_{i, j}$. \\
\hline
\end{tabular}

Table 2. Judgment matrix.

\begin{tabular}{ccccc}
\hline Judgment Index & $\mathbf{a}_{\mathbf{1}}$ & $\mathbf{a}_{\mathbf{2}}$ & $\ldots$ & $\mathbf{a}_{\mathbf{n}}$ \\
\hline $\mathbf{a}_{\mathbf{1}}$ & 1 & $\mathrm{a}_{1,2}$ & $\ldots$ & $\mathrm{a}_{1, \mathrm{n}}$ \\
$\mathbf{a}_{\mathbf{2}}$ & $\mathrm{a}_{2,1}$ & 1 & $\ldots$ & $\mathrm{a}_{2, \mathrm{n}}$ \\
$\ldots$ & $\ldots$ & $\ldots$ & 1 & $\ldots$ \\
$\mathbf{a}_{\mathbf{n}}$ & $\mathrm{a}_{\mathrm{n}, 1}$ & $\mathrm{a}_{\mathrm{n}, 1}$ & $\ldots$ & 1 \\
\hline
\end{tabular}

Moreover, the judgment matrix must meet the condition ai, $\mathrm{j}=1 / \mathrm{aj}, \mathrm{i}$. 
(3) The maximum eigenvalue of the judgment matrix and its corresponding eigenvectors were calculated and a consistency check was performed. If the Consistency Ratio $\left(C_{R}\right)$ was less than 0.1 , it meant that the attributed weights were consistent; otherwise, the judgment matrix was reconstructed. The consistency check equation is as follows:

$$
\begin{gathered}
C_{i}=\frac{\lambda_{\max }-n}{n-1} \\
C_{R}=\frac{C_{i}}{R_{i}}
\end{gathered}
$$

In the equation, $C_{R}$ is the value of the consistency ratio, $C_{i}$ is value of the consistency index, $\lambda_{\max }$ is the maximum eigenvalue of the judgment matrix, $\mathrm{n}$ is the number of indices and RI is the average random consistency index. The $R i$ values are shown in Table 3.

Table 3. Average random consistency index.

\begin{tabular}{cccccccc}
\hline $\boldsymbol{n}$ & $\mathbf{1}$ & $\mathbf{2}$ & $\mathbf{3}$ & $\mathbf{4}$ & $\mathbf{5}$ & $\mathbf{6}$ & $\mathbf{7}$ \\
\hline$R_{i}$ & 0 & 0 & 0.58 & 0.90 & 1.12 & 1.24 & 1.32 \\
\hline
\end{tabular}

\subsubsection{TOPSIS Model and Hot Spot Analysis Model}

(1) TOPSIS Model

The TOPSIS model is also called "approaching the ideal solution sorting method". It is an effective means to solve the multi-objective decision analysis problem of limited schemes in system engineering. It is a comprehensive evaluation method that uses distance as the evaluation standard. By defining a measure in the workspace, the degree to which the target is close to the positive ideal and away from the negative ideal solution is calculated.

$$
\begin{gathered}
Q_{i}^{+}=\sqrt{\sum_{j=1}^{n}\left[W_{j}\left(k_{i j}-k_{j}^{\max }\right)\right]^{2}} \\
(i=1,2, \cdots, n) \\
Q_{i}^{-}=\sqrt{\sum_{j=1}^{n}\left[W_{j}\left(k_{i j}-k_{j}^{\text {min }}\right)\right]^{2}} \\
(i=1,2, \cdots, n)
\end{gathered}
$$

where $Q_{i}^{+}$the distance between the $\mathrm{i}$-th evaluation area and the optimal unit

$Q_{i}^{-} \_$the distance between the $\mathrm{i}$-th evaluation area and the worst unit

$W_{j}$ — the weight of the $\mathrm{j}$-th decision indicator

$k_{i j}$ - the $\mathrm{j}$-th evaluation index score of the $\mathrm{i}$-th evaluation area

$k_{j}^{m a x}$ _ the maximum score of the $j$-th evaluation index

$k_{j}^{\min }$ — the $\mathrm{j}$-th evaluation index minimum score

In this paper, the geological and ecological environment bearing capacity is indicated by the closeness degree of the work. According to the degree of the closeness, the geological and ecological environment bearing capacity of the study area can be determined, and then the order of good and bad is determined. Let $R_{i}$ be the degree to which the bearing capacity of the evaluation area is most close to the optimal area bearing capacity. The value range of $R_{i}$ is between $[0,1]$. The bigger the value of $R_{i}$ is, 
the closer it is to the optimal level of bearing capacity. When the value of $R_{i}$ is at 1 , it indicates that the bearing capacity level is the highest. The calculation formula is as shown in Formula 5.

$$
R_{i}=\frac{Q_{i}^{-}}{Q_{i}^{-}+Q_{i}^{+}}(i=1,2, \cdots, n)
$$

(2) Hot Spot Analysis Model

In the research of determining the characteristics of spatial attributes in related fields, Fan [24] used the natural breakpoint method to evaluate the bearing capacity of resources and environment for the restoration and reconstruction after the Lushan earthquake. Zhao et al. [27] used the spatial clustering method to calculate the quality of cultivated land. Li et al. [28] used a spatial autocorrelation method to analyze the content of $\mathrm{Ni}$ and $\mathrm{Cr}$ in vegetables in the high incidence area of liver cancer in the Pearl River Delta. In order to achieve the organic combination of quality, scale and spatial distribution of regional bearing capacity, this paper chooses hotspot analysis as a method to determine the characteristics of local clustering.

Hotspot analysis (Get-Ord Gi) can calculate the position of high-value and low-value elements in the space, together with the high-low clustering by ArcGIS software. The calculation result $Z$ score represents multiple of standard deviation, which can reflect the discrete of data set degree. A high-value clustering area with a high comprehensive score is a hot spot gathering area. Conversely, a high-value clustering area generated by a region with a lower comprehensive score is a cold spot gathering area. In this paper, the local statistics of regional bearing capacity are analyzed by using Get-Ord Gi local statistics. The hotspot analysis calculation formula is shown in Equations 6, 7, and 8.

$$
G_{i}=\frac{\sum_{i=1}^{n} z_{h i} k_{i}-\bar{X} \sum_{i=1}^{n} z_{h i}}{S \sqrt{\frac{n \sum_{i=1}^{n} z_{h i}{ }^{2}-\left(\sum_{i-1}^{n} z_{h i}\right)^{2}}{n-1}}}
$$

In the formula

$$
\begin{gathered}
\bar{X}=\frac{\sum_{i=1}^{n} k_{i}}{n} \\
S=\frac{\sum_{i=1}^{n} k_{i}{ }^{2}}{n}-\bar{X}^{2}
\end{gathered}
$$

where $G_{i}-$ output statistics of $Z$ score

$k_{i}$ — the index score of the evaluation area $\mathrm{i}$

$z_{h i}$ - evaluate the spatial weight between areas $\mathrm{h}$ and $\mathrm{i}$

$n-$ the total number of evaluation areas

$\bar{X}$ — the average of the index factor scores

$S$ — the standard deviation of index factor score

\subsubsection{Data Preprocessing}

According to the established index system, we referenced some of the index classification standards adopted in relevant home and abroad studies, including GB50218-2014, HJ192-2015, GB50188-2007 [29-31]. Wang et al. [32] researched the bearing capacity of geological and ecological environment. The index layer is quantified by ArcGIS software, and the quantitative results are divided into five levels, with scores of 1, 2, 3, 4, and 5 respectively. The higher the score, the better the bearing capacity index. Otherwise, the worse the bearing capacity index will be. The data processing flow of index factors is shown in Figure 3, Figure 4, and Figure 5. 


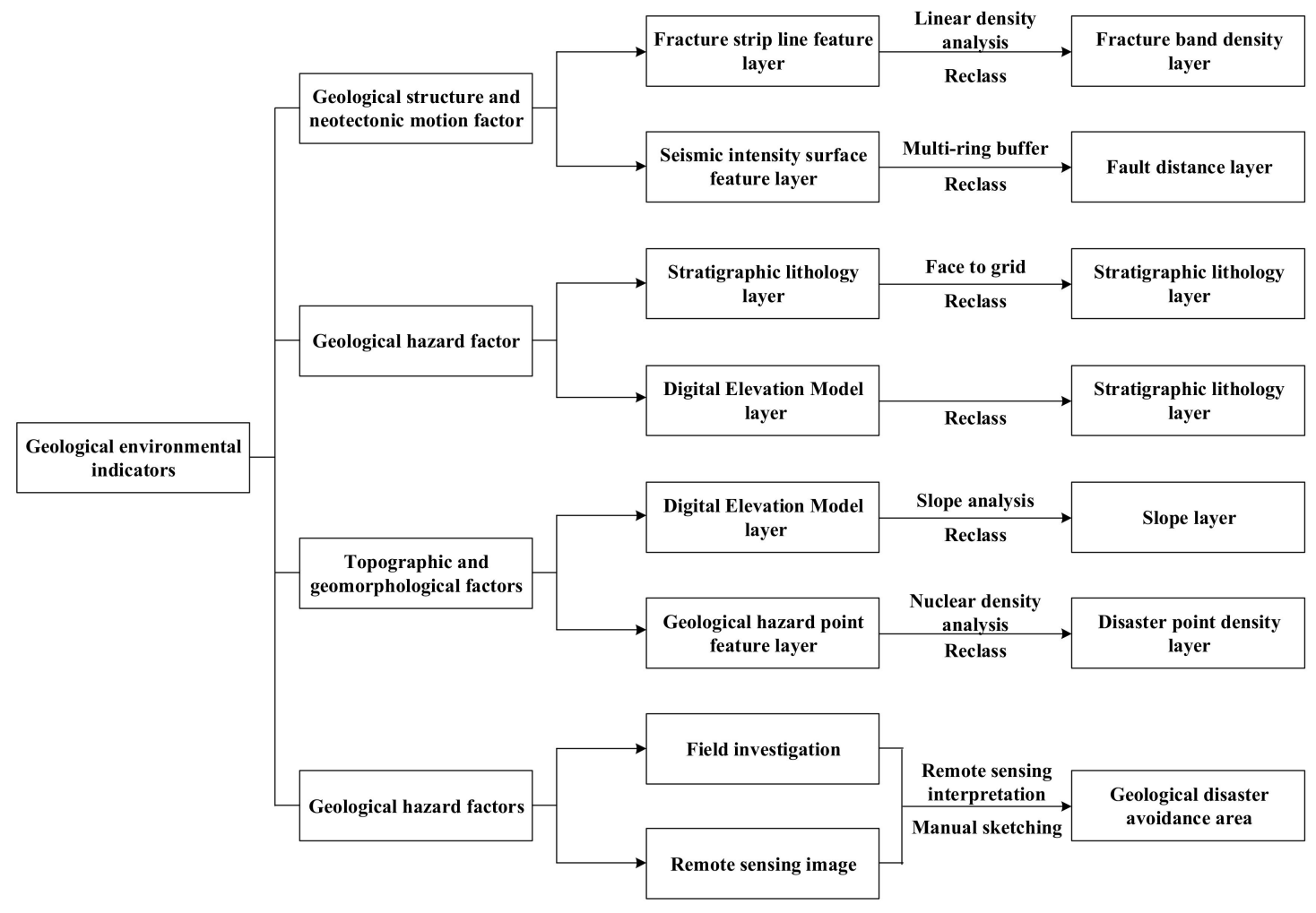

Figure 3. Processing flow chart of geological environment indicators.

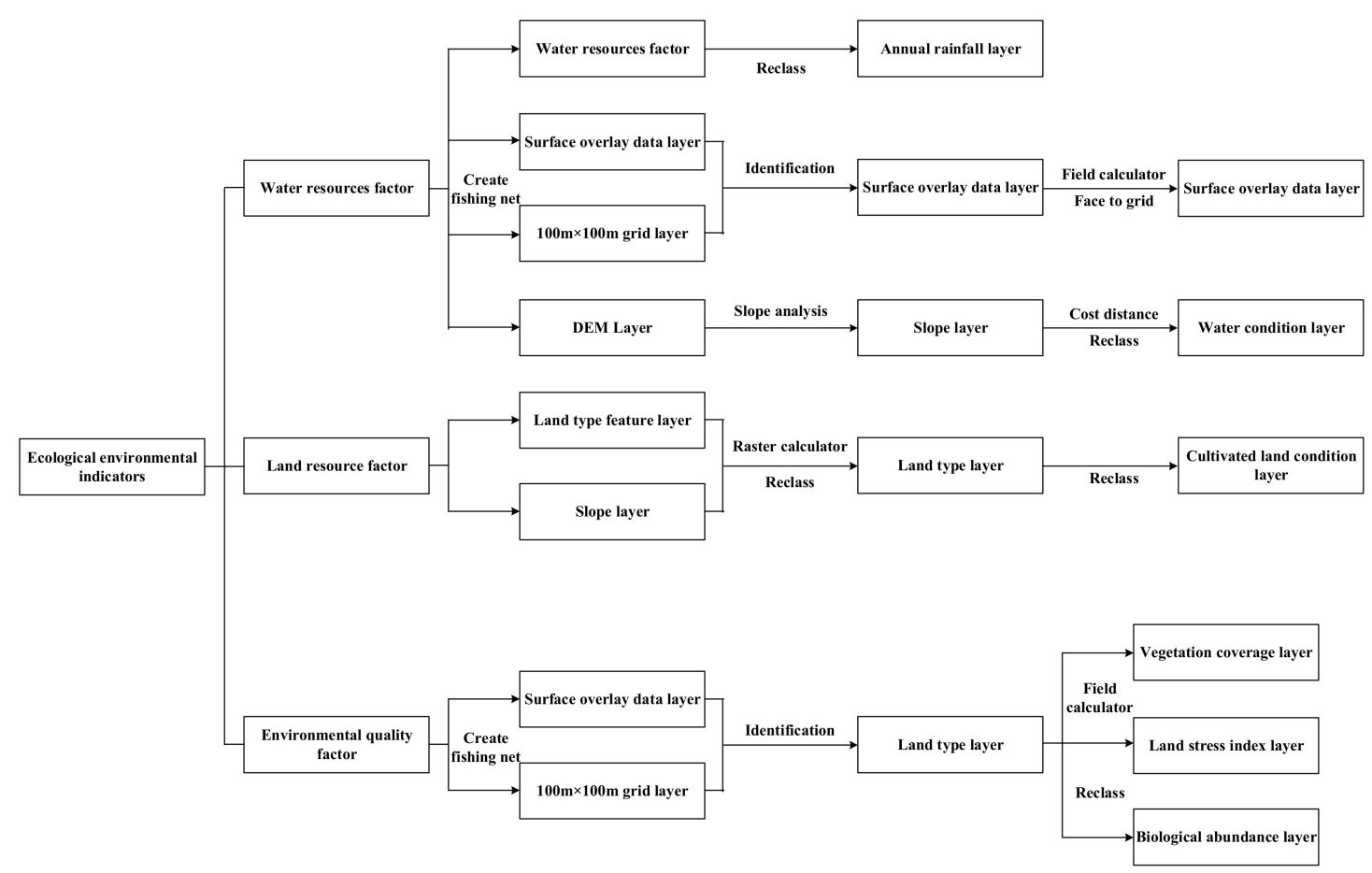

Figure 4. Processing flow chart of eco-environment indicators. 


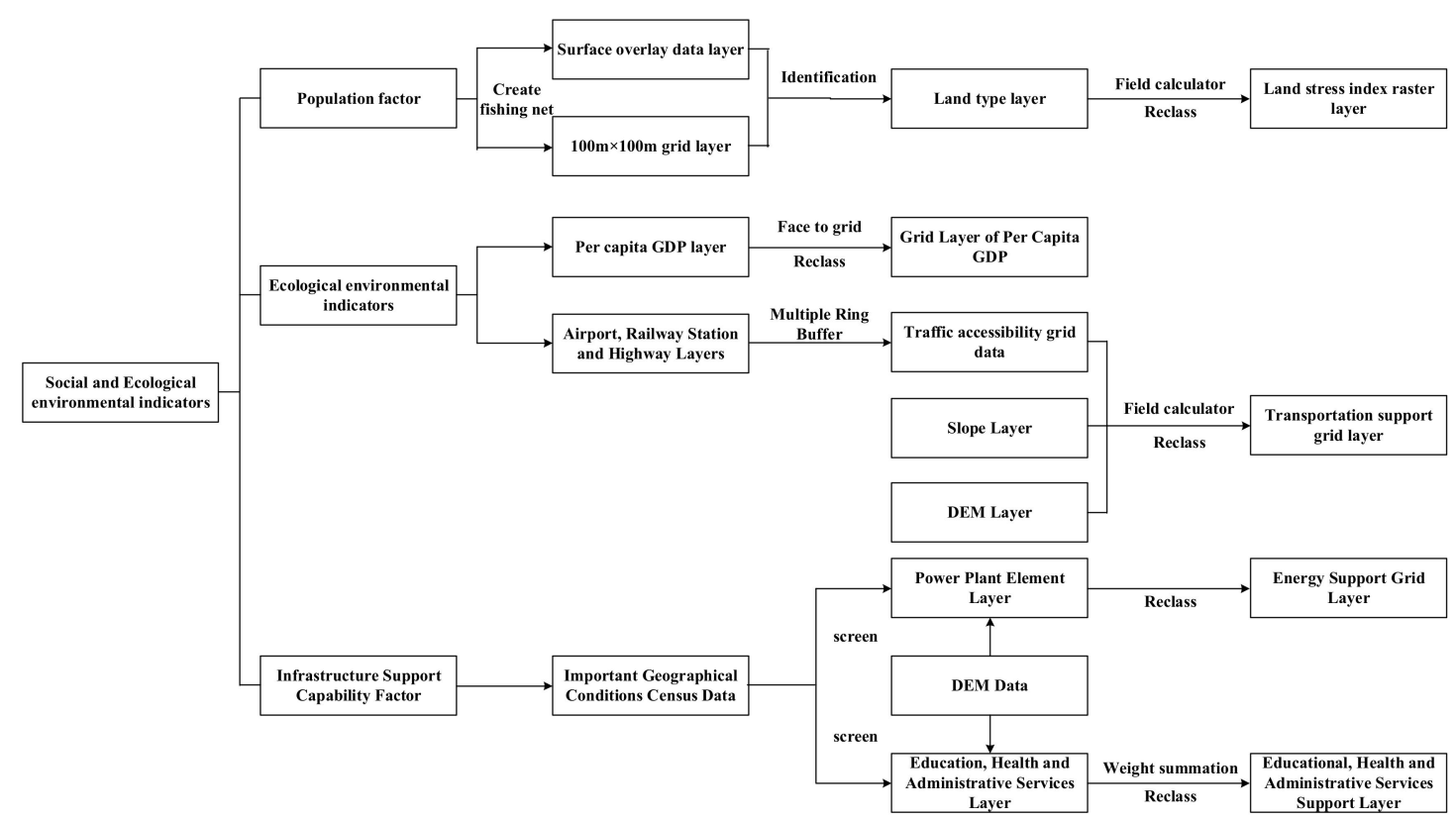

Figure 5. Processing flow chart of social and economic indicators.

\section{Results and Analysis}

\subsection{Determination of Index Weights}

In the research of bearing capacity quality evaluation, the selection and quantification of evaluation indicators is an important step in evaluating regional bearing capacity. The index system method is a widely used evaluation method. The concept of Natural-Economic-Society (NES) comes from the land ecosystem, which consists of multiple layers of subsystems. Moreover, the subsystems are coupled to form the land bearing capacity system. The evaluation index system constructed in this paper is built on top of the national geographical survey results, and it is under the principles of comprehensiveness, dominance, science, regionality, objectivity, combination of qualitative and quantitative, and the principle of inheritance. The selection should reflect the regional bearing capacity in a comprehensive, scientific, and objective manner, and build a multi-level regional bearing capacity assessment index system.

We produced an index score form and sent it to five experts. After multiple rounds of information feedback, we took the median of their scores as the final score for each index and based on the above indices and expert scores, constructed a judgment matrix, as shown in Table 4, Table 5, Table 6, Table 7, Table 8, Table 9, Table 10, Table 11. We used MATLAB to get the index weights of the judgment matrix.

Table 4. Judgment matrix of the criteria layer (layer B).

\begin{tabular}{ccccc}
\hline A & B1 & B2 & B3 & B4 \\
\hline B1 & 1 & 5 & $1 / 2$ & $1 / 2$ \\
B2 & $1 / 5$ & 1 & $1 / 5$ & $1 / 5$ \\
B3 & 2 & 5 & 1 & 1 \\
B4 & 2 & 5 & 1 & 1 \\
\hline$\lambda_{\max }=4.0612, C_{i}=0.0204<0.1, R_{i}=0.9, C_{R}=0.0227<0.1$ \\
\hline
\end{tabular}


Table 5. Judgment matrix of indicator layer (layer C).

\begin{tabular}{|c|c|c|c|c|c|c|c|}
\hline B & $\mathrm{C} 1$ & $\mathrm{C} 2$ & $\mathrm{C} 3$ & C5 & C6 & $\mathrm{C} 7$ & $\mathrm{C} 8$ \\
\hline $\mathrm{C} 1$ & 1 & 7 & 3 & & & & \\
\hline $\mathrm{C} 2$ & $1 / 7$ & 1 & $1 / 5$ & & & & \\
\hline $\mathrm{C} 2$ & $\mathrm{C} 3$ & 5 & 1 & & & & \\
\hline \multicolumn{8}{|c|}{$\lambda_{\max }=3.0655, C_{i}=0.03275<0.1, R_{i}=0.58, C_{R}=0.05646<0.1$} \\
\hline C5 & & & & 1 & 2 & & \\
\hline C6 & & & & $1 / 2$ & 1 & & \\
\hline $\mathrm{C} 7$ & & & & & & 1 & 1 \\
\hline $\mathrm{C} 8$ & & & & & & 1 & 1 \\
\hline
\end{tabular}

The consistency check ratio of the hierarchy total ranking $C_{R}$ was 0.0565 , that is, it was less than 0.1 , and so the consistency check was passed. The weight of the evaluation system of geological environment bearing capacity is shown in Table 6.

Table 6. Weight table of geological environment bearing capacity evaluation system.

\begin{tabular}{cccccc}
\hline Target Layer & Criteria Layer & Weights & Index Layer & Weights & Comprehensive weight \\
\hline & & & $\mathrm{C}_{1}$ & 0.6434 & 0.1408 \\
$\mathrm{~B}_{1}$ & 0.2188 & $\mathrm{C}_{2}$ & 0.0738 & 0.0162 \\
& & $\mathrm{C}_{3}$ & 0.2828 & 0.0619 \\
$\mathrm{~A}$ & $\mathrm{~B}_{2}$ & 0.0623 & $\mathrm{C}_{4}$ & & 0.0623 \\
& & & & 0.6667 & 0.2396 \\
& $\mathrm{~B}_{3}$ & 0.3595 & $\mathrm{C}_{5}$ & 0.1198 \\
& & & $\mathrm{C}_{6}$ & 0.3333 & 0.1797 \\
& $\mathrm{~B}_{4}$ & $\mathrm{C}_{7}$ & 0.5 & 0.1797 \\
\hline
\end{tabular}

Table 7. Judgment matrix of the criteria layer (layer B).

\begin{tabular}{cccc}
\hline $\mathbf{A}$ & $\mathbf{B}_{\mathbf{1}}$ & $\mathbf{B}_{\mathbf{2}}$ & $\mathbf{B}_{\mathbf{3}}$ \\
\hline $\mathrm{B}_{1}$ & 1 & 3 & 1 \\
$\mathrm{~B}_{2}$ & $1 \backslash 3$ & 1 & $1 / 3$ \\
$\mathrm{~B}_{3}$ & 1 & 3 & 1 \\
\multicolumn{2}{l}{$\lambda_{\max }=3, C_{i}=0<0.1, R_{i}=0.58, C_{R}=0<0.1$} \\
\hline
\end{tabular}

Table 8. Judgment matrix of indicator layer (layer C).

\begin{tabular}{|c|c|c|c|c|c|c|}
\hline B & $\mathrm{C}_{1}$ & $\mathrm{C}_{2}$ & $\mathrm{C}_{3}$ & $\mathrm{C}_{5}$ & $\mathrm{C}_{6}$ & $\mathrm{C}_{7}$ \\
\hline $\mathrm{C}_{1}$ & 1 & $1 / 3$ & $1 / 3$ & & & \\
\hline $\mathrm{C}_{2}$ & 3 & 1 & $1 / 2$ & & & \\
\hline $\mathrm{C}_{3}$ & 3 & 2 & 1 & & & \\
\hline \multicolumn{7}{|c|}{$\lambda_{\max }=3.0538, C_{i}=0.0269<0.1, R_{i}=0.58, C_{R}=0.0464<0.1$} \\
\hline $\mathrm{C}_{5}$ & & & & 1 & 2 & 1 \\
\hline $\mathrm{C}_{6}$ & & & & $1 / 2$ & 1 & $1 / 2$ \\
\hline \multirow[t]{2}{*}{$\mathrm{C}_{7}$} & & & & 1 & 2 & 1 \\
\hline & & & & \multicolumn{3}{|c|}{$\lambda_{\max }=3, C_{i}=0<0.1, R_{i}=0.58, C_{R}=0<0.1$} \\
\hline
\end{tabular}

The consistency check ratio of the hierarchy total ranking $C_{R}$ was 0.0232 , that is, it was less than 0.1 , and so the consistency check was passed. The weight of the evaluation system of ecological environment bearing capacity is shown in Table 9 . 
Table 9. Weight table of ecological environment bearing capacity evaluation system.

\begin{tabular}{cccccc}
\hline Target Layer & Criteria Layer & Weights & Index Layer & Weights & Comprehensive weight \\
\hline & & & $\mathrm{C}_{1}$ & 0.1416 & 0.0607 \\
$\mathrm{~B}_{1}$ & 0.4286 & $\mathrm{C}_{2}$ & 0.3338 & 0.1431 \\
& & & $\mathrm{C}_{3}$ & 0.5247 & 0.2249 \\
$\mathrm{~A}$ & $\mathrm{~B}_{2}$ & 0.1428 & $\mathrm{C}_{4}$ & & 0.1428 \\
& & & $\mathrm{C}_{5}$ & 0.4 & 0.1714 \\
& $\mathrm{~B}_{3}$ & 0.4286 & $\mathrm{C}_{6}$ & 0.2 & 0.0857 \\
& & & $\mathrm{C}_{7}$ & 0.4 & 0.1714 \\
\hline
\end{tabular}

Table 10. Judgment matrix of the criteria layer (layer B).

\begin{tabular}{cccc}
\hline $\mathbf{A}$ & $\mathbf{B}_{\mathbf{1}}$ & $\mathbf{B}_{\mathbf{2}}$ & $\mathbf{B}_{\mathbf{3}}$ \\
\hline $\mathrm{B}_{1}$ & 1 & $1 / 2$ & $1 / 2$ \\
$\mathrm{~B}_{2}$ & 2 & 1 & $1 / 2$ \\
$\mathrm{~B}_{3}$ & 2 & 2 & 1 \\
\hline
\end{tabular}

Table 11. Judgment matrix of indicator layer (layer C).

\begin{tabular}{cccc}
\hline B & $\mathbf{C}_{\mathbf{3}}$ & $\mathrm{C}_{\mathbf{4}}$ & $\mathrm{C}_{\mathbf{5}}$ \\
\hline $\mathrm{C}_{3}$ & 1 & 2 & 1 \\
$\mathrm{C}_{4}$ & $1 / 2$ & 1 & $1 / 2$ \\
$\mathrm{C}_{5}$ & 1 & 2 & 1 \\
$\lambda_{\max }=3$, & $C_{i}=0<0.1, R_{i}=0.58, C_{R}=0<0.1$ \\
\hline
\end{tabular}

The consistency check ratio of the hierarchy total ranking $C_{R}$ was 0 , that is, it was less than 0.1 , and so the consistency check was passed. Thus, the weight of social and economic bearing capacity evaluation system is shown in Table 12 .

Table 12. Weight table of social and economic bearing capacity evaluation system.

\begin{tabular}{cccccc}
\hline Target Layer & Criteria Layer & Weights & Index Layer & Weights & Comprehensive weight \\
\hline & $\mathbf{B}_{1}$ & 0.1976 & $\mathrm{C}_{1}$ & & 0.1976 \\
$\mathbf{A}$ & $\mathbf{B}_{\mathbf{2}}$ & 0.3119 & $\mathrm{C}_{2}$ & & 0.3119 \\
& & & $\mathrm{C}_{3}$ & 0.4 & 0.1962 \\
& $\mathbf{B}_{3}$ & 0.4905 & $\mathrm{C}_{4}$ & 0.2 & 0.0981 \\
& & & $\mathrm{C}_{5}$ & 0.4 & 0.1962 \\
\hline
\end{tabular}

\subsubsection{Weight of Geological Environment Index}

In the hierarchical structure chart of geo-environmental bearing capacity evaluation (Figure 6), the geological environment bearing capacity is the target layer (layer A) of the hierarchical structure. The structural elements, geomorphic elements, and other elements are the criteria layer (layer B). The specific slope, high-rise, seismic intensity, and other eight indicators are the indicator layer (layer C) of the hierarchical level.

The consistency check ratio of the hierarchy total ranking $C_{R}$ was 0.0565 , that is, it was less than 0.1 , and so the consistency check was passed. The weight of the evaluation system of geological environment bearing capacity is shown in Table 6 . 


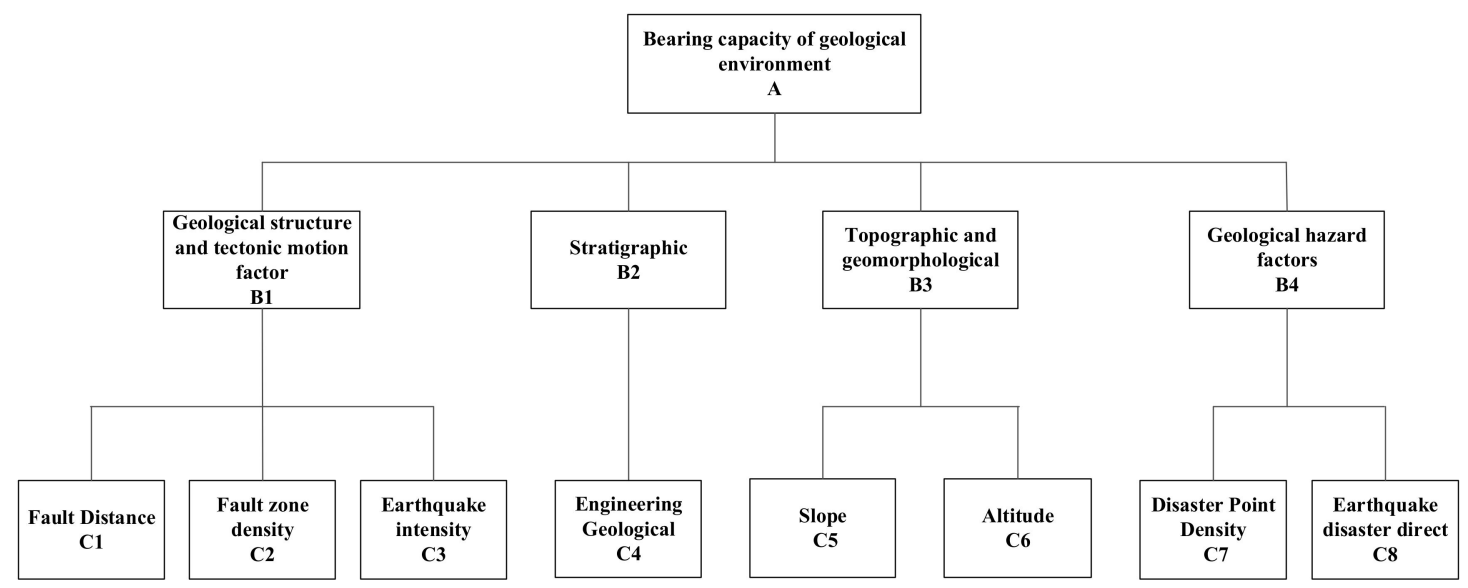

Figure 6. Hierarchical structure of geological environment bearing capacity evaluation.

\subsubsection{Weight of Ecological Environment Index}

In the hierarchical structure chart of eco-environmental bearing capacity evaluation (Figure 7), eco-environmental bearing capacity is the target layer (Layer A) of hierarchical structure, water resource elements, land resource elements, and other elements are the criteria layer (Layer B). Seven indicators, such as annual rainfall, water conservation, and cultivated land conditions are the indicator layer (Layer C) of hierarchical structure.

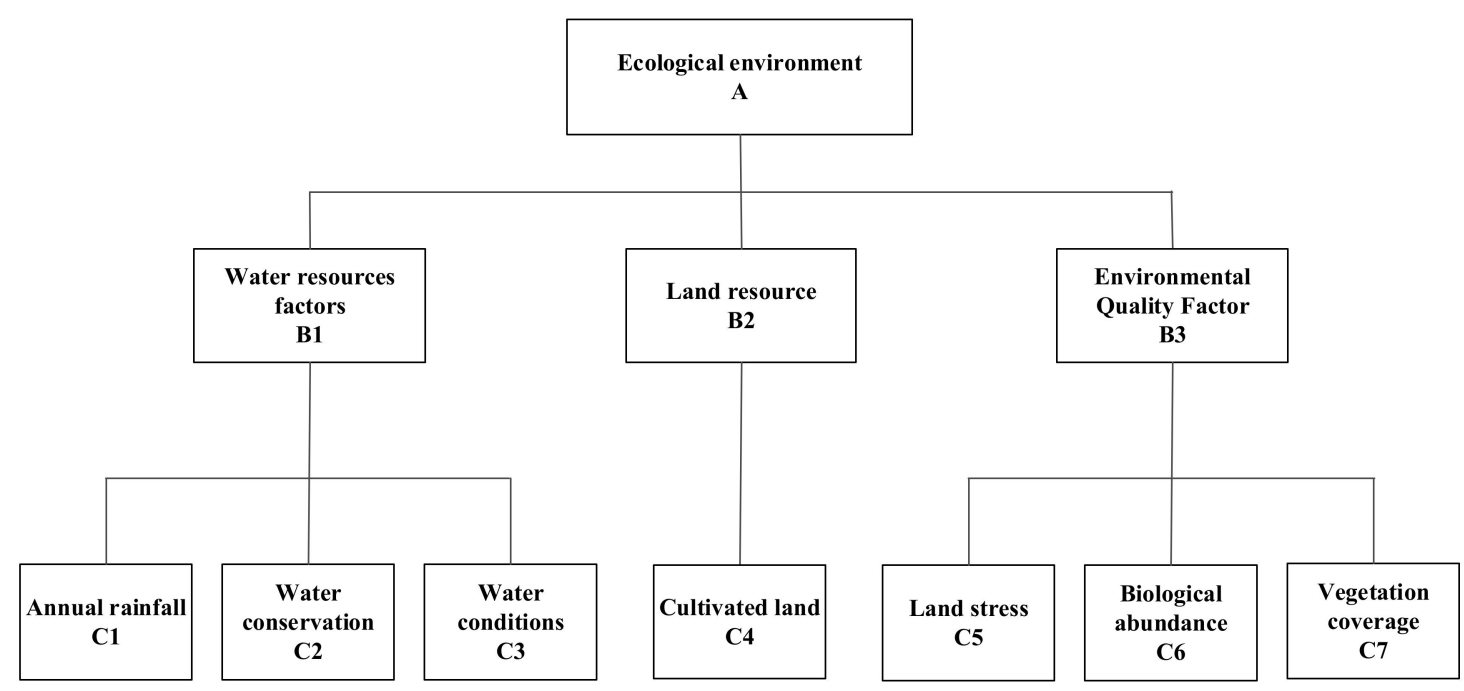

Figure 7. Hierarchical structure of ecological environment bearing capacity evaluation.

The consistency check ratio of the hierarchy total ranking $C_{R}$ was 0.0232 , that is, it was less than 0.1 , and so the consistency check was passed. The weight of the evaluation system of ecological environment bearing capacity is shown in Table 9 .

\subsubsection{Weight of Social and Economic Index}

In the hierarchical structure chart of social and economic bearing capacity evaluation (Figure 8), social and economic bearing capacity is the target layer of hierarchical structure (Layer A). Population factor, economic factor, and infrastructure support factor form the criteria layer (Layer B); five indicators, such as residential area distribution, GDP per capita, and transportation facility support are the indicator layers (Layer C). 


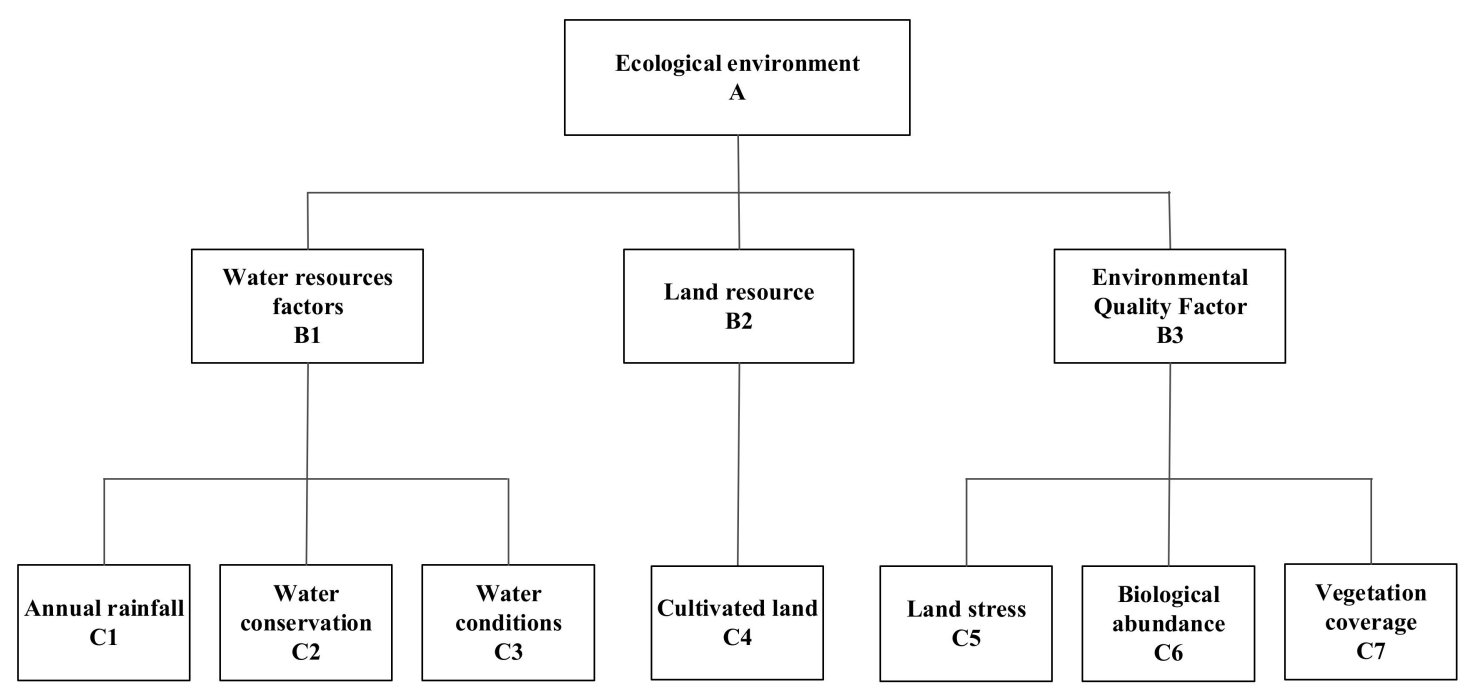

Figure 8. Hierarchical structure of social and economic bearing capacity evaluation.

The consistency check ratio of the hierarchy total ranking $C_{R}$ was 0 , that is, it was less than 0.1 , and so the consistency check was passed. Thus, the weight of social and economic bearing capacity evaluation system is shown in Table 12.

\subsection{Comprehensive Quality Evaluation of Bearing Capacity}

First, the distance between each index layer grid unit and the optimal unit and the worst unit is calculated by using the grid calculator. The positive and negative ideal solutions of geological environment subsystem, ecological environment subsystem, social economy subsystem, and comprehensive bearing capacity are obtained by weighted superposition. Secondly, the grid calculator is used to calculate the corresponding closeness degree, and the natural breakpoint method is used to divide the load-bearing status closeness degree score into five grades I, II, III, IV, and V, which are converted into vector data for spatial distribution clustering research. The closeness degree score is shown in Figure 9.

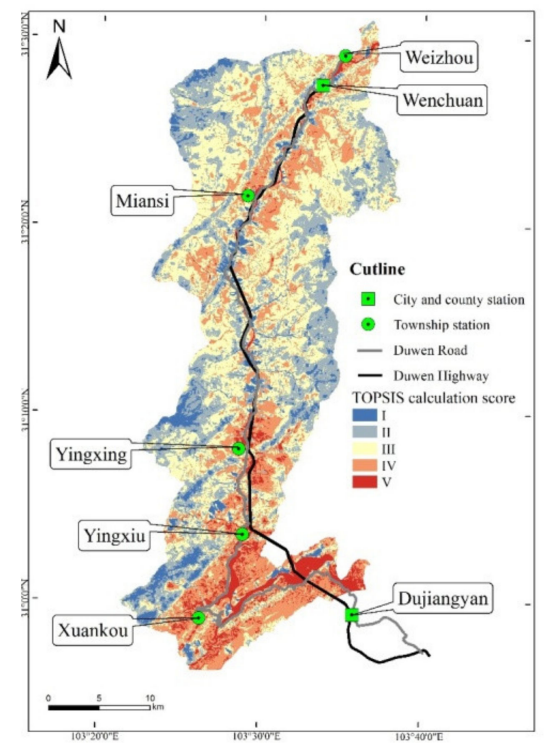

Figure 9. Closeness degree score of comprehensive assessment of geological and ecological environment. 
Among them, the areas of Grade I, II, III, IV, and V are $61.93 \mathrm{~km}^{2}, 233.74 \mathrm{~km}^{2}, 345.82 \mathrm{~km}^{2}$, $222.82 \mathrm{~km}^{2}$, and $61.3 \mathrm{~km}^{2}$ respectively, accounting for $6.69 \%, 25.25 \%, 37.36 \%, 24.07 \%$, and $6.62 \%$ of the total area each.

\subsection{Local Clustering Result}

The hot spot analysis is used to calculate the closeness scores of the geological environment, ecological environment, socioeconomic, geological, and ecological environment comprehensive bearing capacity evaluation. The results of how high-valued and low-valued areas clustered in the calculation are divided into 7 levels: 99\% confidence hotspot clustering (high and high neighboring), 95\% confidence hotspot clustering (high and middle neighboring), 90\% confidence hotspot clustering (middle and middle neighboring), which is not significant, $99 \%$ confidence cold spot clustering area (low and low neighboring, 95\% confidence cold spot clustering zone (low and middle neighboring), $90 \%$ confidence cold spot clustering zone (high and low neighboring). Red zone represents high value clustering zone and blue zone represents the low. The value aggregation area is shown in Figure 10.

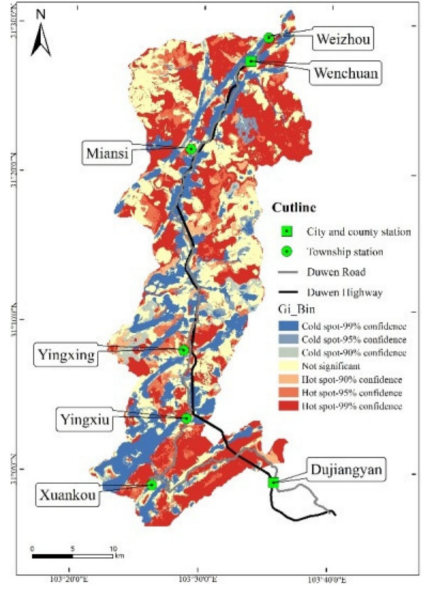

(a)

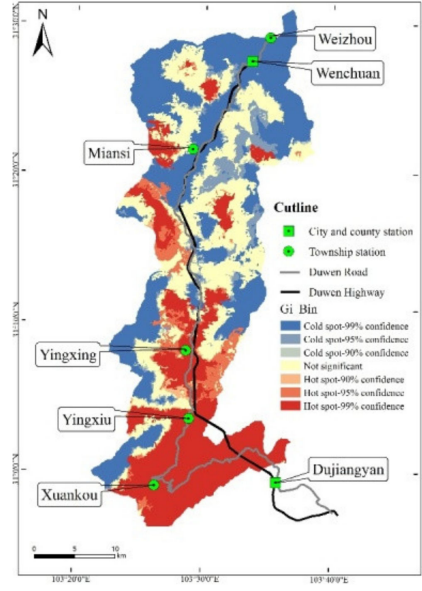

(b)

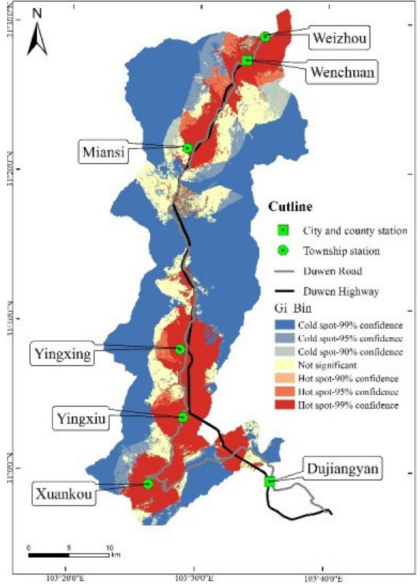

(c)

Figure 10. (a) Results of hotspot analysis: for hot spot analysis of geological environment subsystem; (b) hot spot analysis of ecological environment subsystem; (c) hotspot analysis of social economic subsystem.

As for the subsystem of geological environment, the regional geological bearing capacity of Xuankou Town, Zipingpu Town and the main stream of Minjiang River in the study area are clustered in high value. In the northwest direction of Xuankou Town, the debris flow channel and its outburst areas, such as Qipan Ditch and Taoguan Ditch, as well as the geological environment bearing capacity near Maowen fault zone (Longmen Mountain back the mountain fault) and Yingxiu fault zone, are low-value aggregated. The geological hazards in the region include debris flow, landslides, and earthquakes. The hot spot area is $430.55 \mathrm{~km}^{2}$ and the cold point area is $234.95 \mathrm{~km}^{2}$, as shown in Figure 10a.

As for the subsystem of ecological environment, the triangle area composed of Dujiangyan City, Yingxiu and Xuankou towns in the southern part of the study area shows high value aggregation, while the high mountain and forest areas in the northern part of the study area also show local high value aggregation. The high-altitude snow cover area in the northwest corner of Miansi Town, the high-drop vegetation-free growth area in the southwest corner of Ginkgo Township, and the area around Wenchuan County are low-value aggregation areas. The hot spot area is $317.16 \mathrm{~km}^{2}$ and the cold point area is $373.02 \mathrm{~km}^{2}$, as shown in Figure 10b.

As for social and economic subsystems, because of the relatively concentrated population in cities and towns, and the relatively complete construction of transportation, energy, and infrastructure, 
public service departments, such as hospitals and schools, are basically concentrated in the town center. The social and economic bearing capacity in space takes the town as the center, and tends to weaken outward, in accordance with the principle of attenuation. The central area of the town and the area along Du-Wen Road show high value aggregation, while the areas far from the central area of the town and the mountainous areas with higher elevation show low value aggregation. The hot area is $260.17 \mathrm{~km}^{2}$, and the cold point area is $531.95 \mathrm{~km}^{2}$, as shown in Figure 10c.

\subsection{Graded Result}

According to the calculation results of hot spot analysis, the low-low neighboring and low-middle neighboring clustering regions are defined as unsuitable construction areas according to their spatial distribution characteristics of low-value aggregation. The high-low neighboring and middle-middle neighboring clustering regions and random distribution regions are designated as backup reserve areas. The high-middle neighboring and high-high neighboring regions are designated as suitable construction areas, for their spatial distribution characteristics of high-value aggregation, as shown in Figure 11.

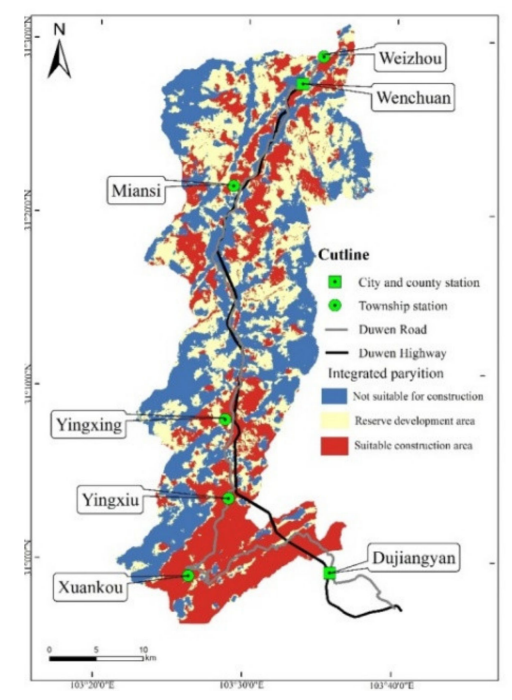

Figure 11. Comprehensive partitioning.

The bearing capacity of geological and ecological environment along Du-Wen Road has distinctive spatial clustering characteristics. In general, the bearing capacity of Xuankou Town and Yingxiu Town along the main stream of Minjiang River in the south is better than that of Weizhou Town and Miansi Town in the north. The bearing capacity is obviously low in the vicinity of faults and where debris flow, landslide, and other geological disasters have happened. Among them: the total area suitable for construction is $288.38 \mathrm{~km}^{2}$, accounting for $31.12 \%$ of the total area of the region; the total area of the reserve development area is $296.35 \mathrm{~km}^{2}$, accounting for $31.98 \%$ of the total area of the region; the total area unsuitable for construction area is $340.87 \mathrm{~km}^{2}$, accounting for $36.79 \%$ of the total area of the region.

\section{Conclusions}

This paper selects the area along the mountain road with characteristics of geological disasters as the research area, and combines the research results of existing bearing capacity with the first national geographical survey of Sichuan Province, and adds geological environmental factors to construct a reflection research area. The evaluation index system of different aspects of geological and ecological environment bearing capacity is determined by the AHP method. The data is pre-processed by ArcGIS software. The TOPSIS method and superimposed analysis tool are used to quantitatively evaluate the 
geological and ecological environment bearing capacity of the study area. The following conclusions are obtained:

(1) Based on the comprehensive quality evaluation of the bearing capacity of the study area and thinking from a spatial perspective, the priority scores are calculated by hot spot analysis tools. According to the calculation results, the study area is divided into suitable construction area, backup reserve area, and unsuitable construction area. From the perspective of the spatial distribution of the construction area, the bearing capacity of Xuankou Town and Yingxiu Town along the southern Minjiang River is superior to that of Weizhou Town and Miansi Town in the north. The research provides a new idea for the zoning planning of the comprehensive evaluation of regional bearing capacity.

(2) The zoning results consider the bearing capacity relationship among the quality-scale-space distribution. The evaluation results not only consider the development suitability from the perspective of comprehensive quality, but also consider the spatial stability of sustainable development from the perspective of spatial layout. It is of great significance for optimizing the development pattern and resource allocation of land space.

(3) After the Wenchuan Earthquake in 2008 and Lushan Earthquake in 2013, the mountain environment, especially the geological environment, has become more fragile in Sichuan. Therefore, to investigate the current situation and characteristics of the geological ecological environment and analyze its bearing capacity, has become an important premise for highway management departments to formulate safe operation and management strategies, and for township construction planning departments to reasonably develop and utilize the limited environmental resources along the mountain highway, which is a work of great practical significance.

Author Contributions: Author Contributions: Conceptualization, Zhoufeng Wang and Chen Zhang; methodology, Zhoufeng Wang and Chen Zhang; software, Zhoufeng Wang; validation, Zhoufeng Wang and Jianwei Xu; formal analysis, Zhoufeng Wang and Xiangqi He; investigation, Yujun Wang; resources, Zhoufeng Wang; data curation, Zhoufeng Wang and Chen Zhang; writing — original draft preparation, Zhoufeng Wang, Chen Zhang; writing—-review and editing, Zhoufeng Wang, Chen Zhang, Yujun Wang, Jianwei Xu, and Xiangqi He; visualization, Zhoufeng Wang and supervision, Zhoufeng Wang, Chen Zhang, and Xiangqi He. All authors have read and agreed to the published version of the manuscript.

Funding: The work was supported by General Program of Chongqing science and Technology Bureau (Grant No.cstc2019jscx-msxmX0311), funding Plan for Young Teachers of Southwest Petroleum University (201131010020).

Acknowledgments: We sincerely appreciate the Editor's encouragement and the anonymous reviewer's valuable support.

Conflicts of Interest: The authors declare no conflicts of interest.

\section{References}

1. Ma, C.M.; Ma, Y.H. Tentative investigation of bearing capacity of geological environment for sustainable development. Environ. Sci. Technol. 2007, 30, 64-65.

2. Liu, J.J.; Dong, S.C.; Li, Z.H. Comprehensive evaluation of China's water resources carrying capacity. J. Nat. Resour. 2011, 26, 258-269.

3. Liu, M.H.; Zhao, S.; Yang, X.H. Dynamic evaluation of regional comprehensive carrying capacity in Henan Province. Areal Res. Dev. 2014, 33, 31-36.

4. Lu, J.T.; Lu, D.M.; Liu, H.P. Analysis of ecological environment resources carrying capacity of Guiyang City. Chin. J. Agric. Resour. Reg. Plan. 2014, 35, 24-28.

5. Li, Z. Land Ecological Safety Warning of Mountain Plain Transitional Area-Case Study of Dujiangyan City. Ph.D. Thesis, Chengdu University of Technology, Chengdu, China, 2012.

6. Wang, Y.Q.; Guo, J.J.; Li, K. Spatial-temporal dynamic analysis of the biocapacity pattern in the mountain area of upper Shiyang river catchment. J. Lanzhou Univ. 2013, 49, 166-172.

7. Liu, J.X.; Chen, L.J.; Huang, Q.H. Evaluation of Geo-environmental carrying capacity of Wulonggou mine based on spatial statistical analysis method. Met. Mine 2017, 4, 162-166.

8. Yang, L.; Peng, H.Y.; Zhou, M. Assessment of geological environment carrying of capacity Fengjie County based on AHP. J. Chongqing Jiaotong Univ. 2014, 33, 95-99. 
9. Yang, Q.; Yu, C.P.; Zhou, F. An emergy-ecological footprint model based evaluation of ecological security at the industrial area in Northeast China, A case study of Liaoning Province. Chin. J. Appl. Ecol. 2016, 27, 1594-1602.

10. Zheng, H.; Shi, P.J.; He, J.J. THE dynamic on ecological footprint and ecological capacity of Gansu Province. J. Arid Land Resour. Environ. 2013, 27, 13-17.

11. Gu, K.K. The concept of ecological carrying capacity and its research methods. Ecol. Environ. Sci. 2012, 21, 389-395.

12. Xu, Y.Y.; LI, G.Z.; Xu, W. Dynamic evaluation of traffic environmental bearing capacity if Beijing and diagnosis of obstacle factor. J. Highw. Transp. Res. Dev. 2017, 34, 122-127.

13. Wang, Z.F.; Zhang, T.S.; Wang, C.W. Prediction model and its application for glacial lake outburst in the Himalayas area, Tibet. J. Glaciol. Geocryol. 2016, 38, 388-394.

14. Ni, Z.Y. Study on the Eco-Geological Environment Carrying Capacity of Qushi-Sangri Area in Tibet. Ph.D. Thesis, Chengdu University of Technology, Chengdu, China, 2011.

15. Tong, X.; Gan, Y.Q.; Xia, Y. Assessment and zoning of the geological environment in the city of Wuhan. Hydrogeol. Eng. Geol. 2015, 42, 149-155.

16. Wang, Z.F.; Zhang, T.S.; Wang, L. The integrated assessment system of eco-geological environmental carrying capacity for Dujiangyan-Wenchaun highway. Sci. Surv. Mapp. 2016, 41, 77-81.

17. Ma, Z.; Xie, H.; Lin, L. Analysis of geological conditions of land, resources and environment in Beijing Tianjin Hebei region. Geol. China 2017, 44, 857-873.

18. Jiang, Y.; Lin, L.; Chen, L. Resource and environmental conditions and major geological problems of the Yangtze River Economic Belt. Geol. China 2017, 44, 1045-1061.

19. Zhang, M.; Wang, Y. Theory and evaluation method of bearing capacity of geological environment based on risk. Geol. Bull. China 2018, 37, 467-473.

20. Meng, H.; Zhang, R.; Shi, J.; Li, C. Safety assessment of geological environment. Earth Sci. 2019. [CrossRef]

21. Rapport, D.J.; Costanza, R.; McMichael, A. Assessing ecosystem health. Trends Ecol. Evol. 1998, 13, $397-402$. [CrossRef]

22. Zhu, J.; Lu, H.; Wang, H. Ecosystem health assessment in Wenchuan earthquake disaster area during recovery period. Acta Ecol. Sin. 2018, 38, 9001-9011.

23. Tang, M.; Liu, B.; Li, S. Review and Prospect of the research on the bearing capacity of resources and environment-For the mountainous area with severe topography after the earthquake. J. Fuzhou Univ. 2016, 30, 10-13.

24. Fan, J. Evaluation of Carrying Capacity of Resources and Environment for Restoration and Reconstruction after Lushan Earthquake; Science Press: Beijing, China, 2014.

25. Saaty, T.L. The Analytic Hierarchy Process: Planning, Priority Setting, Resource Allocation; McGraw-Hill: New York, NY, USA, 1980.

26. Saaty, T.L. Analytical Planning the Organization of Systems; Pergamon Press: New York, NY, USA, 1985.

27. Zhao, D.L.; He, S.S.; Yang, J.Y. Quality potential calculation of arable land consolidation based on limiting factors and hot spot analysis. Trans. Chin. Soc. Agric. Mach. 2017, 48, 158-164.

28. Li, Y.; Zhou, Y.Z.; Zhang, C.B. Application of local Moran's I and GIS to identify hotspots of Ni, Cr of vegetable soils in high-incidence area of liver cancer from the pearl river delta, South China. Environ. Sci. 2010, 31, 1617-1623.

29. Ministry of Housing and Urban-Rural Development of People's Republic of China. General Administration of Quality Supervision Inspection and Quarantine of the People's Republic of China. Standard of engineering Classification of Rock Mass, (GB50218-2014); Standard Press of China: Beijing, China, 2014.

30. Ministry of Environment Protection of the People's Republic of China. Technical Criterion for Eco-Environmental Status Evaluation, (HJ192-2015); Environment Press of China: Beijing, China, 2015. 
31. Ministry of Housing and Urban-Rural Development of People's Republic of China. General Administration of Quality Supervision Inspection and Quarantine of the People's Republic of China. Standards for Planning of Town, (GB50188-2007); Standard Press of China: Beijing, China, 2007.

32. Wang, Z.F.; Wang, Y.J.; Wang, L. Research on the comprehensive evaluation system of eco-geological environmental carrying capacity based on the analytic hierarchy process. Clust. Comput. 2017, 10, 1-10. [CrossRef]

(C) 2020 by the authors. Licensee MDPI, Basel, Switzerland. This article is an open access article distributed under the terms and conditions of the Creative Commons Attribution (CC BY) license (http://creativecommons.org/licenses/by/4.0/). 